\title{
A THREE DECADE MIXED METHOD BIBLIOMETRIC INVESTIGATION OF IEEE TRANSACTIONS ON ENGINEERING MANAGEMENT
}

Giacomo Marzi, Lincoln International Business School, University of Lincoln, (UK)

Andrea Caputo, Lincoln International Business School, University of Lincoln, (UK)

Edwin Garces, Portland State University, Portland, OR, (USA)

Marina Dabić, Faculty of Economics and Business, University of Zagreb, (Croatia)

\& Nottingham Trent University, Nottingham, (UK)

PUBLISHED IN: IEEE Transactions in Engineering Management

\begin{abstract}
This paper offers a comprehensive overview of IEEE Transactions in Engineering Management (IEEE TEM) from 1985 to 2017. The article employs a mixed method examination based on an indepth interview with the new editor regarding the challenges for the future of IEEE TEM, along with a bibliometric analysis of the journal. By using Web of Science Core Collection data, the analysis maps the knowledge produced and disseminated by the IEEE TEM, revealing the most cited papers; the most frequently occurring keywords and the interconnection between them; the most prolific authors and their co-authorship network; and the most prolific countries for published articles. The paper also shows the main avenues of research covered by IEEE TEM and their evolution through the analysis of the correlation of keywords. This paper offers an example application of a mixed method bibliometric analysis, seeking to extend the quantitative findings by including other sources of data.
\end{abstract}

\section{Introduction}

IEEE Transactions on Engineering Management (IEEE TEM) is a leading international journal in the field of Technology and Engineering Management. It was created in 1954 with the support of the IEEE Transactions on Engineering Management Society and is published by the Institute of Electrical and Electronic Engineers. IEEE TEM has an impact factor of 1.418 (August 2018), and it is indexed within major databases used by scholars across a range of different fields.

In this instance, we present a bibliometric study of IEEE TEM following a major change in the editorial team, with the appointment of a new editor and several new co-editors. In fact, it is typical for a journal to organize a special activity when celebrating an anniversary or a change in its editorial team and this kind activity is often publicized in the form of a bibliometric overview [1].

Moreover, considering that it has been more than sixty years since the first issue of the journal, a paper briefly summarizing the knowledge produced by the IEEE TEM in the last 30 years is both desirable and justified. In fact, while an increase in knowledge is always a good thing, constant research can render it rather difficult for scholars to remain up to date on all of the relevant studies published in their respective fields. It is therefore commonplace for scholars, either at regular intervals or when prompted by an editorial board change, to be invited to perform a bibliometric analysis of the field or the journal in order to take stock of the journal's situation [2], [3]. Consequently, in adopting a bibliometric approach, the present study aims to be informative in providing a retrospective evaluation of the results of IEEE TEM.

In doing so, the paper is structured as follows: in next section we present the methodology used for the analysis of IEEE TEM from 1985 to 2017; in Section Three we present an interview with the new 
editor in order to provide a detailed point of view on the future challenges that IEEE TEM will face; in Section Four we present the results of the bibliometric analysis, which are divided into three main timeframes; and, finally, in the last section we summarize the results and trace possible future research avenues for the journal.

\section{Methods}

This paper is split into two different parts. The first part is qualitative and contains an interview of the editor in chief. The second part is quantitative and focuses on the detailed bibliometric analysis of the journal from 1985 to 2017. Moreover, in order to provide a detailed overview of the topic's evolution over the years, we decided to divide the bibliometric analysis into three-time frames. The first is from 1985 to 1995; the second is from 1996 to 2006; and the third is from 2007 to 2017. In the next paragraphs, we discuss the methodology used and then go on to present the results of our analysis.

\subsection{Methodological notes about the interview process}

Although it is mostly used in marketing research, methodological literature argues that in-depth semistructured interviews can be fundamental to obtaining additional narrative information. Semistructured interviews also allow scholars to analyze the emotions and experiences of the interviewed individual [4]. The protocol consisted of a series of open-ended questions about the previous academic experience of the interviewed person, his past roles in directing academic journals, his thoughts about the future of Engineering Management as field of study, his experiences in developing research and projects in the field of Engineering Management, and his thoughts about how he could use his expertise to lead IEEE TEM [5].

To formulate the interview plot, authors had to first take into consideration examples of interviews emerging from major international business journals, such as Harvard Business Review, Financial Times, and Fortune. After the reviewing process, a preliminary set of questions were prepared. However, to assess the scope of the interview, the set of questions was adapted and checked against other interviews conducted with editors in academic fields such statistics, chemistry, and medicine [6]-[8]. Finally, the interview guide was revised by an external independent reviewer. The interview occurred on $16^{\text {th }}$ May 2018 in Portland (US).

\subsection{Methodological notes about bibliometric analysis}

The bibliometric analysis of IEEE TEM started with the data collection of papers published in the journal between 1985 and 2017. From this, the Thomson Reuters Web of Science Core Collection database was selected, as it offers the most valuable and high-impact collection of data and is recognized as the most reliable database for bibliometric studies [9], [10]. The research query was IS=(0018-9391) where "IS" is the ISSN number of the target journal. The selection was restricted to "Article" and "Review" document types to avoid editorials, notes, and corrections.

The whole database for the current study is thus comprised of 1291 peer-reviewed papers covering the period from 1985 to 2017 . The data collection was done on $14^{\text {th }}$ March 2018 and, in order to ensure the inclusion of all relevant data, a cross-validation was made with Scopus and EBSCO Business Premier.

For the bibliometric analysis in this instance, VOSviewer 1.6.8 was used. In order to offer a comprehensive snapshot, we proposed a co-word analysis and a co-author analysis of the three time frames selected (1998-1995, 1996-2006, and 2007-2017). As outlined by Zupic and Čater [11], the co-word analysis is a content analysis technique which utilizes certain key terms to inaugurate relationships in order to form a conceptual structure. This approach stems from the idea that if a word frequently occurs within several documents, then it can be assumed that the documents are closely related as they interrogate similar concepts. This method is the only one that assesses the content of a document to formulate a measure of similarity, as other methods make more periphrastic connections through co-authorships or citations within a document. Co-word analysis ultimately 
produces a network of themes and maps their relationship onto a conceptual space representing a particular field. This semantic map aids researchers in comprehending its cognitive structure [12]. The production of several maps spanning across different time periods allows alterations to this conceptual space to be monitored [13]. In this particular case, co-word analysis has been applied to the keywords given from the authors to each manuscript.

On the other hand, co-author analysis rests on the assumption that social networks are created when scientists collaborate to produce scientific articles [14]. Co-authoring a scientific publication is deemed to be a measure of collaboration and thus, when two authors publish a paper together, a relationship is established [15]. The bond of co-authorship is seen to establish a stronger social connection than other measures, thus giving co-author analysis more authority in detecting social networks than the analysis of intellectual structures within research fields. Furthermore, bibliographic data often includes information regarding an author's geographical location and institutional affiliation and, as such, co-author analysis has increasingly been used to analyze the collaboration network between countries.

The VOS technique displays the results arising from a co-occurrence matrix, namely visualization of similarities. Co-occurrences are the result of the presence, frequency, and proximity of similar pairs of terms in data, in our case keywords and authors [16]. The mathematical process behind the routine begins with the construction of a similarity matrix, obtained by normalizing a co-occurrence matrix of items [17]. Secondly, the script performs a set of routines to build a two-dimensional map in which the items 1 to $n$ are positioned to such a degree that their placement represents the distance between any pair of items $x$ and $y$, reflecting their similarities in term of cited references. In addition to this, a cluster density view is performed with additional mathematical steps [17]. When the items' density is calculated, each cluster is associated with a color. This is done by computing a weighted average of the colors, where the weight of a color equals the item density for the corresponding cluster [17]. In doing this, VOS analysis can display a large amount of information in a single graphical plot. The map built by the text-mining routine is a plot in which the items' distance can be interpreted as an indication of the relatedness of the terms - the smaller the distance between the terms, the stronger the terms are related to each other [16]. Furthermore, the cluster analysis highlights the knowledge base's diversity in an aggregate way. If keywords or authors belong to the same cluster, it means that they are strongly linked together as a group on the basis of their similarities, indicating that a cluster represents a stream of research or a particular topic on a similarity basis. Finally, the size of a point represents the normalized citation value of a unit of analysis, showing its relative importance in the plot and the field under study [16].

\section{The new path of IEEE TEM}

Before undertaking the bibliometric exploration of IEEE TEM, in order to gather relevant information concerning the journal, the authors interviewed the new Editor-in-Chief of IEEE Transactions on Engineering Management Journal as of 2018. The interview addresses questions about the profile, objectives, and characteristics of the Journal and the following information corresponds to essential topics defining its scope and future.

\section{What exactly is the philosophy behind IEEE Transactions on Engineering Management? What sets it apart from other journals?}

IEEE Transactions on Engineering Management publishes original research in the form of research articles in the area of Managing Engineering and Technology. The journal covers a wide variety of methodologies as well as application areas, but the common domain is Managing Engineering and Technology. Accordingly, these methodologies can range from field surveys, hypothesis testing, multivariate analysis, etc, to expert judgment quantification, analytical work, optimization, modelling simulation, case study analysis, decision analysis, and so on and so forth.

The journal mainly focuses on Engineering and Technology Management. In this context, the application areas include energy, healthcare, construction industry, and manufacturing. The most 
important characteristic is that the topic has to touch on engineering and technology. Therefore, with technology currently existing to some extent in almost every industry, we are interested in how to manage the challenges faced when introducing new technology. For example, in the sports industry, travel, or tourism, new areas analyze how finance or block-chain impacts the financial sector, security, or information security; however less attention is paid to developing security models as we instead look at how it is managed.

Why should authors publish with IEEE Transactions on Engineering Management? What is the main audience of the journal?

First of all, the reputation of the journal goes back over fifty years, and the journal is known as the world's leading journal in Engineers Management. In comparison to the reputations of other journals focusing on Engineering and Technology Management, it is well known in both engineering and business schools. Moreover, it has been read by professionals in the fields of both engineering and technology. There are therefore two main audiences for the journal: half in the academic sector and half in the government industry.

What are the most valuable assets of the journal?

The most valuable asset, of course, is the journal's history as well the association behind it. This is comprised of the IEEE, the editorial team, and the authors.

As the new editor of IEEE Transactions on Engineering Management, what is the new editorial line that you would like to bring into the journal? Are there any directions in which you would like the journal to go?

The areas that were considered before were People and Organizations; Information Technology; Complex Socio-technical and Engineering Projects; Electronic Business and Analytics; Models and Methodologies; Social Issues and Sustainability in Engineering Management; Technology, Innovation Management; and Entrepreneurship, and Manufacturing and Supply Chain. These have been rethought and we now focus on three main areas: Engineering Management, Emerging Technologies, and Technology Management.

Engineering Management is well established and covers both the identification and implementation of successful projects and systems; developing from engineer to leader, and marketing the challenges of regulations, policies, standards, and designs.

We are trying to expand in Technology Management as this area is in a state of constant and significant growth. This field considers the perspectives of technology assessment, forecasting, planning, and transfer; managing technology innovation; new product and service development; research and development management; and entrepreneurship. The area thus covers two significant groups: moving products/services from an idea to the market; and integrating technology for capability and productivity.

More specifically, we emphasize the role of Emerging Technologies, which focuses on technologies that are currently appearing and growing, such as artificial intelligence, internet of things, and space travel.

In your opinion, what challenges will IEEE Transactions on Engineering Management face in the next few years?

The main issue will be bringing in new areas and fields of research. It is also extremely difficult to attract research from experts in the area and convince colleges that this is the most prominent journal publishing on Technology Management.

\section{IEEE Transaction on Engineering Management: a bibliometric analysis}

This section presents the results of a bibliometric analysis on 1291 papers published on IEEE TEM from 1985 to 2017. 
From 1985 to 1990, the journal was consistently publishing an average of 20-25 articles every year. This number has grown substantially since the 90 s to the point where the journal is currently publishing around 50 documents per year, (see Figure 1). This increasing number of published articles correlates with the massive growth of researchers and scientists worldwide who are producing an increasing amount of research material [11].

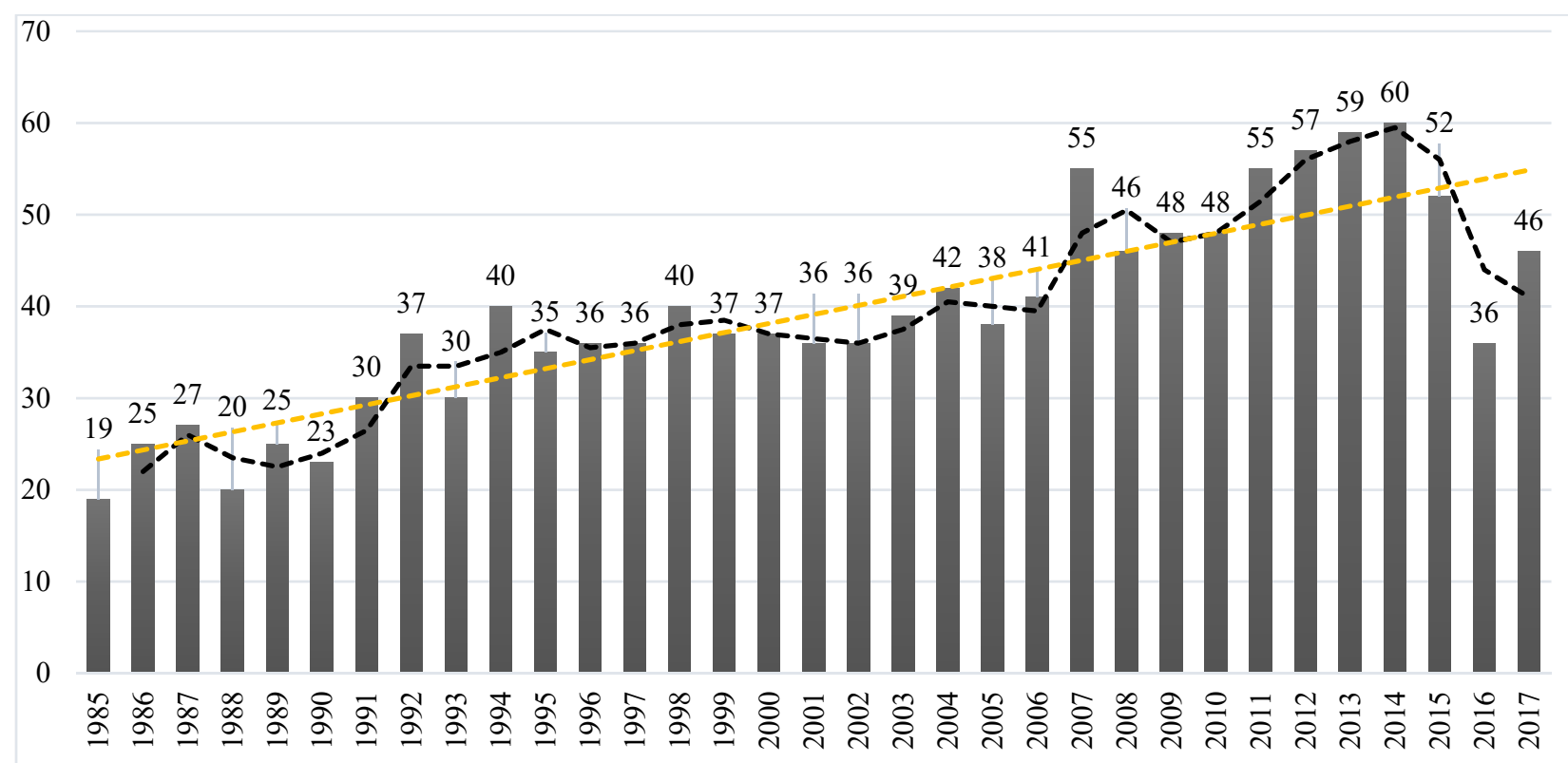

Figure 1 - Papers distribution among the years

The next sections will utilize a series of acronyms; the meanings of which can be found in the following table (Table 1):

\begin{tabular}{|l|l|}
\hline Key & Meaning \\
\hline OC & Keyword occurrences. How many times a keyword appears. \\
\hline APY & $\begin{array}{l}\text { Average publication year of a keyword. The average year when a keyword is used } \\
\text { in the selected time frame. }\end{array}$ \\
\hline ND & $\begin{array}{l}\text { Number of documents published by an author or the sum of published documents } \\
\text { published by scholars from a specific country. }\end{array}$ \\
\hline TC & $\begin{array}{l}\text { Number of citations of an author or the sum of citations by scholars from a specific } \\
\text { country. }\end{array}$ \\
\hline NC & Normalized citations. The weighted number of citations published in that year. \\
\hline Cluster & The cluster in which a specific keyword, author, or country belong to. \\
\hline Links & The number of links in the network of a keyword, author, or country. \\
\hline \multicolumn{1}{|c|}{ Table 1 - Keys used in the bibliometric analysis } \\
\hline
\end{tabular}

Table 2 presents the most cited papers published between 1985 and 2017. Because of the long timespan of the dataset, normalized citations (NC) were utilized when ordering the papers, selecting papers with at least 40 normalized citations.

As shown, the review from Browning [18] is both the most cited paper (TC) and the most normalized cited paper (NC). This particular review draws conclusions concerning both the benefits of the design structure matrix (DSM) in practice and the obstacles arising from its use. New DSM applications and potential future research directions are also highlighted.

The second paper, by Balachandra and Friar [19], is another review of the critical factors that can indicate the success or failure of R\&D projects along with new product introductions. The review demonstrates that, even when adopting a more conservative approach when outlining significant factors, the list is quite substantial. Secondly, in comparing the factors across a range of different studies, it becomes evident that different authors have unearthed discrepancies in both the direction 
of influence and the magnitude of significance. Finally, the meanings of similar factors can also be seen to vary, when considering the differences in context. A contingency framework for the new product and the R\&D project models is thus proposed by the authors.

The third paper on the list, by Pinto and Mantel [20], identifies a set of managerial factors which are associated with project failure. The authors were able to show that the factors that were associated with failure relied on the perceived definition of failure, suggesting that a better understanding of how project managers define both failure and success is necessary.

The fourth paper, by Lichtenthaler [21], is a quantitative paper which shows that firms have increasingly begun to commercialize technological knowledge, opposing normal technological transactions. These vital exchanges, occurring with a firm, contrast traditional approaches to innovation, which are often more closed in nature. This contradictory new paradigm has thus been branded 'open innovation'. This is an integrated perspective, based on data collected from a questionnaire-based study of 154 firms. In this study, the status of open innovation in practice is defined and firms' strategic approaches to technology transactions along the innovation process are identified.

The fifth paper on the list is by Badiru [22] and similarly presents a computational survey which assesses the many univariate and multivariate learning curve models which have been seen to evolve over recent years. The models can potentially be used for productivity assessment in engineering management, or for cost analysis.

The sixth paper, by Craighead et al. [23], is another literature review wherein the authors analyze the common method variance. Recent research employing surveys were analyzed from IEEE TEM, the Journal of Operations Management, and Production and Operations Management in order to establish if and how scholars were able to approach CMV findings which did not overtly address CMV, along with those that did address CMV and yet relied on remedies that were relatively weak.

The seventh paper, by Gefen et al. [24], is the first quantitative survey research on the list analyzing the role of a technology acceptance model for an e-commerce website. In particular, the paper found that repeat customers trusted the e-vendor more and perceived the website to be more useful and easy to use.

The eighth paper, by Keeney and Vonwinterfeldt [25], analyzed the role of the expert in technical analyses of complex problems. Based on around 1000 probability distributions assessed from about 40 experts from universities, consulting firms, and national laboratories, the paper analyzed the processes and procedures for obtaining and using expert judgments, and found that they are often inadequate.

The ninth paper, by Henriksen and Traynor [26], proposes an improved scoring tool for research and development, project evaluation, and selection. The proposed scoring algorithm incorporates tradeoffs among the evaluation criteria, and calculates a relative measure of project value. Moreover, a comprehensive overview of the most recent R\&D project-selection literature is included.

Finally, the tenth paper, by Mustafa and Albahar [27], shows how the analytic hierarchy process can be used to analyze and assess project risks during the bidding stage of a construction project to overcome the limitations of the traditional approaches currently used by contractors.

Moving on from these results, it is reasonable to assume that reviews and papers that take stock of a particular field of study are likely to receive more citations in the long run. However, Table 2 shows that older papers do not necessarily receive more citations than newer ones (see columns entitled NC and TC), showing that high impact research is not positively influenced by the time in which it was completed.

\begin{tabular}{|l|l|l|l|l|l|}
\hline Author(s) & Title & $\begin{array}{l}\text { Vol., Issue, } \\
\text { Page }\end{array}$ & Year & NC & TC \\
\hline Browning, Tr & $\begin{array}{l}\text { Applying the design structure matrix to } \\
\text { system decomposition and integration } \\
\text { problems: a review and new directions }\end{array}$ & $48(3), 292-306$ & 2001 & 108,02 & 652 \\
\hline
\end{tabular}




\begin{tabular}{|c|c|c|c|c|c|}
\hline $\begin{array}{l}\text { Balachandra, R; Friar, } \\
\text { Jh }\end{array}$ & $\begin{array}{l}\text { Factors for success in R\&D projects and new } \\
\text { product innovation: a contextual framework }\end{array}$ & $44(3), 276-287$ & 1997 & 89,75 & 264 \\
\hline Pinto, Jk; Mantel, Sj & The causes of project failure & $37(4), 269-276$ & 1990 & 81,32 & 169 \\
\hline Lichtenthaler, U & $\begin{array}{l}\text { Open innovation in practice: an analysis of } \\
\text { strategic approaches to technology } \\
\text { transactions }\end{array}$ & $55(1), 148-157$ & 2008 & 81,22 & 208 \\
\hline Badiru, Ab & $\begin{array}{l}\text { Computational survey of univariate and } \\
\text { multivariate learning-curve models }\end{array}$ & $39(2), 176-188$ & 1992 & 76,73 & 152 \\
\hline $\begin{array}{l}\text { Craighead, Christopher } \\
\text { W.; Ketchen, David J., } \\
\text { Jr.; Dunn, Kaitlin S.; } \\
\text { Hult, G. Tomas M. } \\
\end{array}$ & $\begin{array}{l}\text { Addressing common method variance: } \\
\text { guidelines for survey research on information } \\
\text { technology, operations, and supply chain } \\
\text { management }\end{array}$ & $58(3), 578-588$ & 2011 & 72,84 & 89 \\
\hline $\begin{array}{l}\text { Gefen, D; Karahanna, } \\
\text { E; Straub, Dw }\end{array}$ & $\begin{array}{l}\text { Inexperience and experience with online } \\
\text { stores: the importance of TAM and trust }\end{array}$ & $50(3), 307-321$ & 2003 & 69,88 & 296 \\
\hline $\begin{array}{l}\text { Keeney, Rl; } \\
\text { Vonwinterfeldt, D }\end{array}$ & $\begin{array}{l}\text { Eliciting probabilities from experts in complex } \\
\text { technical problems }\end{array}$ & $38(3)$, & 1991 & 69,19 & 146 \\
\hline $\begin{array}{l}\text { Henriksen, } \mathrm{Ad} \text {; } \\
\text { Traynor, } \mathrm{Aj}\end{array}$ & A practical R\&D project-selection scoring tool & $46(2), 158-170$ & 1999 & 67,19 & 152 \\
\hline $\begin{array}{l}\text { Mustafa, Ma; Albahar, } \\
\text { Jf }\end{array}$ & sment using the analytic & $38(1), 46-52$ & 1991 & 63,03 & 133 \\
\hline $\begin{array}{l}\text { Tatikonda, } \mathrm{Mv} \\
\text { Rosenthal, } \mathrm{Sr}\end{array}$ & $\begin{array}{l}\text { Technology novelty, project complexity, and } \\
\text { product development project execution } \\
\text { success: a deeper look at task uncertainty in } \\
\text { product innovation }\end{array}$ & $47(1), 74-87$ & 2000 & 59,23 & 219 \\
\hline Might, Rj; Fischer, Wa & $\begin{array}{l}\text { The role of structural factors in determining } \\
\text { project-management success }\end{array}$ & $32(2), 71-77$ & 1985 & 56,16 & 47 \\
\hline Saleh, Sd; Wang, Ck & $\begin{array}{l}\text { tion - strategy, } \\
\text { 1-climate }\end{array}$ & $40(1), 14-21$ & 1993 & 54,97 & 70 \\
\hline $\begin{array}{l}\text { Green, Sg; Gavin, Mb; } \\
\text { Aimansmith, L }\end{array}$ & $\begin{array}{l}\text { Assessing a multidimensional measure of } \\
\text { radical technological innovation }\end{array}$ & 42(3), 203-214 & 1995 & 51,69 & 175 \\
\hline Shenhar, Aj & $\begin{array}{l}\text { From theory to practice: toward a typology of } \\
\text { project-management styles }\end{array}$ & $45(1), 33-48$ & 1998 & 48,97 & 77 \\
\hline Allen, $\mathrm{Tj}$ & $\begin{array}{l}\text { Organizational-structure, information } \\
\text { technology, and r-and-d productivity }\end{array}$ & $33(4), 212-217$ & 1986 & 48,14 & 57 \\
\hline Kangari, R; Riggs, Ls & Construction risk assessment by linguistics & $36(2), 126-131$ & 1989 & 47,34 & 114 \\
\hline Kostoff, Rn; Scaller, Rr & Science and technology roadmaps & $48(2), 132-143$ & 2001 & 46,88 & 283 \\
\hline Meade, La; Presley, A & $\begin{array}{l}\text { R\&D project selection using the analytic } \\
\text { network process }\end{array}$ & $49(1), 59-66$ & 2002 & 46,66 & 256 \\
\hline $\begin{array}{l}\text { Davis, Fd; Venkatesh, } \\
\text { V }\end{array}$ & $\begin{array}{l}\text { Toward preprototype user acceptance testing } \\
\text { of new information systems: implications for } \\
\text { software project management }\end{array}$ & $51(1), 31-46$ & 2004 & 43,72 & 127 \\
\hline
\end{tabular}

Table 2 - Twenty most cited paper from 1985 to 2017 (ordered with normalized citations)

Moving on from this, we examine the paper published by IEEE TEM dividing our analysis into three periods: 1998-1995; 1996-2006; and 2007-2017.

\section{$4.11985-1995$}

There are, at present, 418 papers indexed in WOS Core Collection. Unfortunately, the database did not index keywords until 1992. As a result, the co-word analysis of the keyword would be biased and centered on the last three years of the time span. We have therefore decided not to include the keyword analysis for the first period, between 1985 and 1995.

Nonetheless, the database permitted us to perform the other two planned analyses. In fact, the next figure (Figure 2) presents the co-author network analysis, showing the collaborations amongst authors during the period under analysis. 


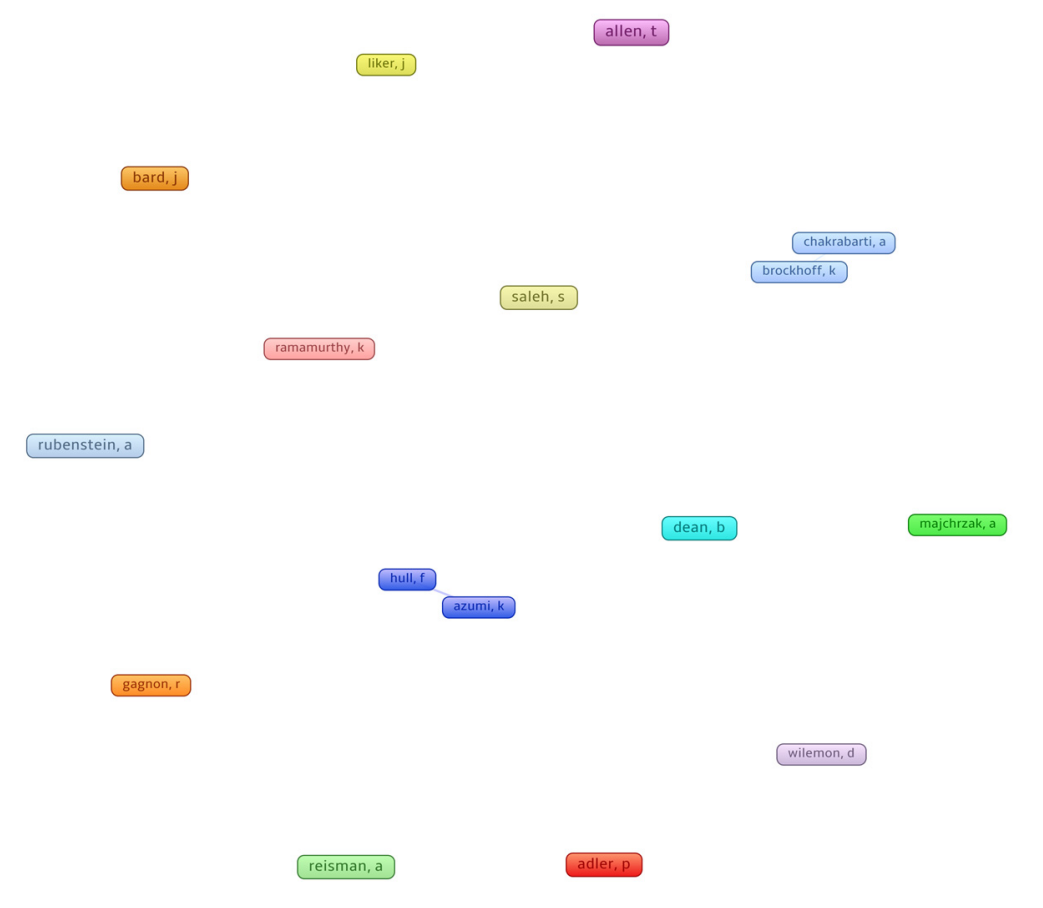

Figure 2 - Main authors distribution and connections for the period 1985 - 1995

\begin{tabular}{|l|c|c|c|c|}
\hline \multicolumn{1}{|c|}{ Author } & ND & TC & Cluster & Links \\
\hline Allen, T & 5 & 170 & 4 & 0 \\
\hline Adler, P & 4 & 135 & 3 & 0 \\
\hline Bard, J & 4 & 99 & 5 & 0 \\
\hline Saleh, S & 4 & 89 & 13 & 0 \\
\hline Reisman, A & 4 & 81 & 11 & 0 \\
\hline Rubenstein, A & 4 & 49 & 12 & 0 \\
\hline Dean, B & 4 & 41 & 6 & 0 \\
\hline Ramamurthy, K & 3 & 132 & 10 & 0 \\
\hline Wilemon, D & 3 & 124 & 14 & 0 \\
\hline Brockhoff, K & 3 & 74 & 1 & 1 \\
\hline Chakrabarti, A & 3 & 72 & 1 & 1 \\
\hline Liker, J & 3 & 39 & 8 & 0 \\
\hline Azumi, K & 3 & 36 & 2 & 1 \\
\hline Hull, F & 3 & 36 & 2 & 1 \\
\hline Majchrzak, A & 3 & 26 & 9 & 0 \\
\hline Gagnon, R & 3 & 15 & 7 & 0 \\
\hline
\end{tabular}

Table 3 - Details of the main authors' distribution and connections for the period 1985 - 1995

Both Figure 2 and Table 3 show that the connections between authors are weak in the period between 1985 and 1995. The only relevant connections are between Brockhoff, K. and Chakrabarti, A. (Cluster 1) and Azumi, K. and Hull, F. (Cluster 2). It is surprising that authors with a relevant number of papers (e.g. Allen, T.) are not relevantly linked with other authors. This result shows that, in the period under analysis, the main authors tended to be very dynamic, avoiding writing more than one paper with the same person. This finding is positive because it shows that top authors are likely to have a large network; however, this could have negative effects in the long run because it does not permit the creation of specific schools of thought. 
However, it is important to specify that the lack of connections amongst the authors is exclusively in terms of their involvement with the IEEE TEM journal - the same authors may have published together in other journals. This caveat is valid also for the other two author analyses shown in Figure 5 and Figure 8.

Moving on to the next figure, we now present the authors' connections based on the country of their institutions (Figure 3 and Table 4).

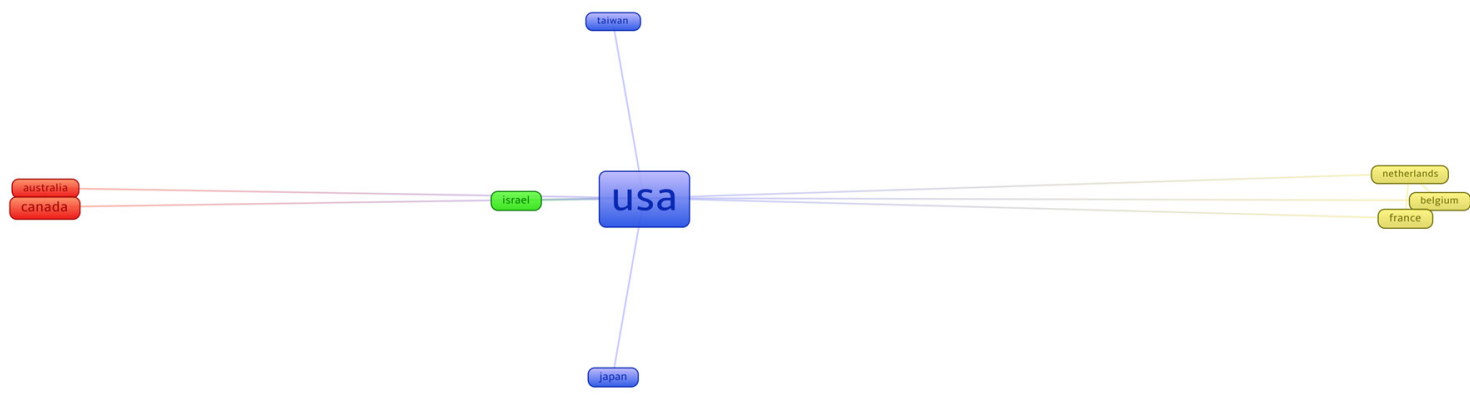

Figure 3 - Main countries' distribution and connections for the period 1985 - 1995

\begin{tabular}{|l|l|l|l|l|}
\hline Country & ND & TC & Cluster & Links \\
\hline USA & 135 & 3200 & 2 & 8 \\
\hline Canada & 17 & 171 & 3 & 2 \\
\hline France & 4 & 200 & 1 & 3 \\
\hline Israel & 4 & 77 & 4 & 1 \\
\hline Australia & 4 & 12 & 3 & 2 \\
\hline Japan & 3 & 51 & 2 & 1 \\
\hline Netherlands & 2 & 128 & 1 & 3 \\
\hline Belgium & 1 & 118 & 1 & 3 \\
\hline Taiwan & 1 & 11 & 2 & 1 \\
\hline
\end{tabular}

Table 4 - Details of main countries' distribution and connections for the period 1985 - 1995

Both Figure 3 and Table 4 show that US-based scholars are predominantly the main contributors of IEEE TEM, with a total number of 135 documents. Canada, in second place, has only 17 papers (a difference of 118 papers) and, in joint third place, France and Israel have only four papers. However, despite France having only four papers, it collects 200 citations, which average out to approximately 50 citations per paper, while the US collects an average of only 23.70 citations per paper. It shows that, while France based scholars produced a small number of papers, these papers were high in impact. The same can be said for the Netherlands, with only 2 papers but 128 citations (an average of 64 citations per paper); and Belgium, with 118 citations to only one paper.

When considering the above statistics, it is important to note that, when a paper is co-authored by a US based scholar and a Belgian based scholar, both countries receive the same amount of citations.

\section{$4.21996-2006$}

In the 1996 to 2006 time span, 418 papers were indexed in the WOS Core Collection. The next figure (Figure 4) shows the main authors' keywords assigned to their papers. This analysis permits us to understand the main topic discussed in the period under analysis. Table 5 also presents the main data related to selected keywords appearing at least two times. 


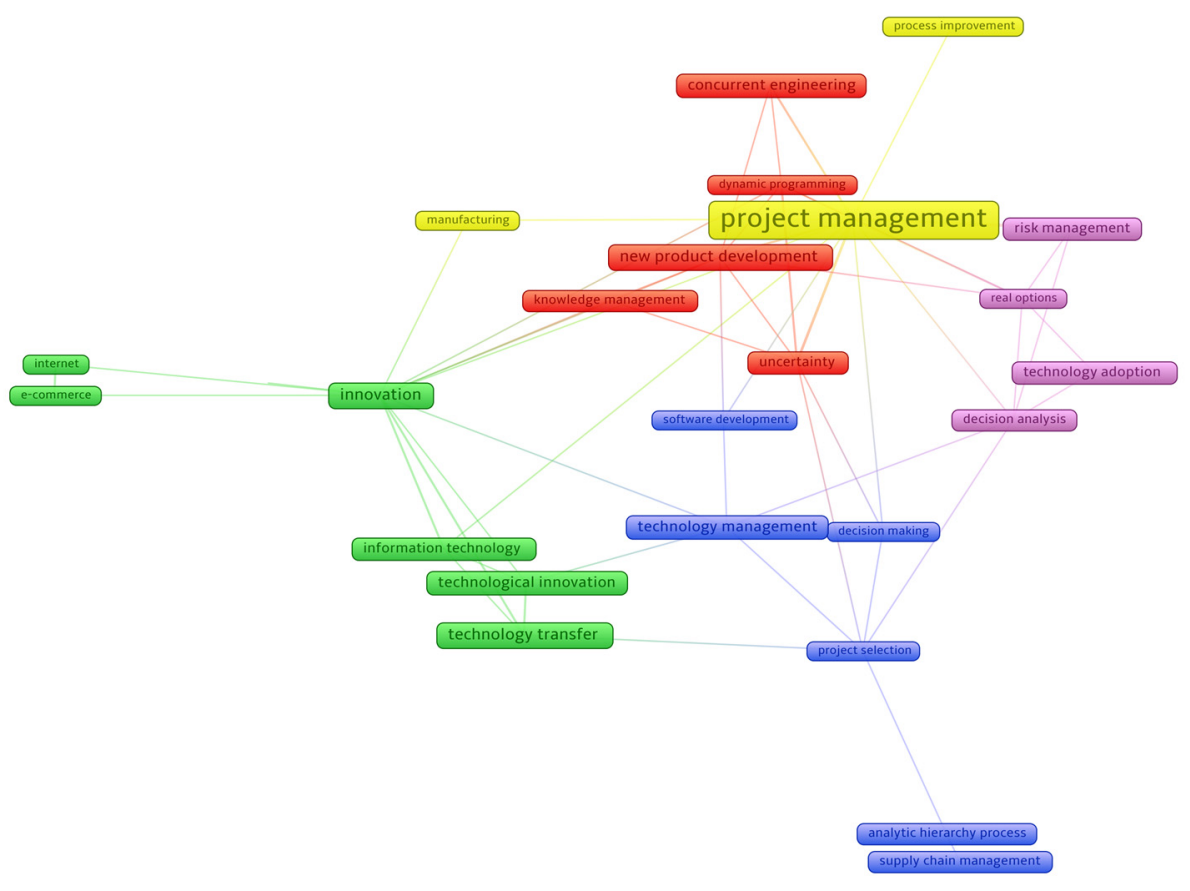

Figure 4 - Distribution of main keywords for the period 1996 - 2006

\begin{tabular}{|c|c|c|c|c|}
\hline Keywords & OC & Cluster & Links & APY \\
\hline project management & 33 & 5 & 13 & 2002,67 \\
\hline innovation & 13 & 1 & 12 & 2001,23 \\
\hline new product development & 13 & 3 & 8 & 2000,69 \\
\hline technology transfer & 13 & 1 & 4 & 1999,46 \\
\hline technological innovation & 11 & 1 & 4 & 1999,82 \\
\hline technology management & 10 & 2 & 5 & 1999,70 \\
\hline concurrent engineering & 10 & 3 & 3 & 2000,40 \\
\hline information technology & 9 & 1 & 4 & 1998,11 \\
\hline technology adoption & 9 & 4 & 2 & 2001,56 \\
\hline uncertainty & 8 & 3 & 6 & 2001,63 \\
\hline risk management & 8 & 4 & 3 & 2001,50 \\
\hline decision analysis & 7 & 4 & 6 & 2002,14 \\
\hline knowledge management & 7 & 3 & 3 & 2002,43 \\
\hline supply chain management & 7 & 2 & 1 & 2002,57 \\
\hline analytic hierarchy process & 6 & 2 & 2 & 1999,50 \\
\hline project selection & 5 & 2 & 6 & 2000,80 \\
\hline dynamic programming & 5 & 3 & 6 & 2000,80 \\
\hline real options & 5 & 4 & 6 & 2004,40 \\
\hline decision making & 5 & 2 & 3 & 2000,60 \\
\hline software development & 5 & 2 & 3 & 2003,00 \\
\hline e-commerce & 5 & 1 & 2 & 2003,40 \\
\hline internet & 5 & 1 & 2 & 2003,60 \\
\hline manufacturing & 5 & 5 & 2 & 2001,60 \\
\hline research and development & 5 & 1 & 1 & 2000,20 \\
\hline process improvement & 5 & 5 & 1 & 2003,60 \\
\hline
\end{tabular}

Table 5 - Details of the distribution of main keywords for the period $1996-2006$

As shown, all keywords are centered around "project management." This keyword belongs to the dominant cluster (yellow), showing that most of the topics analyzed on IEEE TEM are strongly connected with issues related to project management. The second keyword, "innovation," which belongs to Cluster 1 (green), represents another area of intrigue. This keyword shares many 
connections with the others and creates an important cluster together with "technology transfer" and "technological innovation," showing that these topics are often discussed together in IEEE TEM. The next cluster $(3$, red) is dominated by "new product development," "concurrent engineering," and "uncertainty." However, even if these keywords do not belong to the same cluster of "project management," Figure 4 shows them to be close together on the map, which tells us that the scholars do not directly speak about project management, but it is implied as an overarching topic.

Cluster 2 (blue) is dominated by "technology management," "supply chain management," and "analytic hierarchy process," showing that these concepts are often discussed together in IEEE TEM. Finally, Cluster 4 (purple) is dominated by "technology adoption," "risk management," and "decision analysis." This shows that a high amount of scholars are particularly sensible to the risk connected with decision-making and risks emerging from the adoption of new technology.

Figure 5 and Table 6 analyze the authors' network collaborations in the period under analysis.

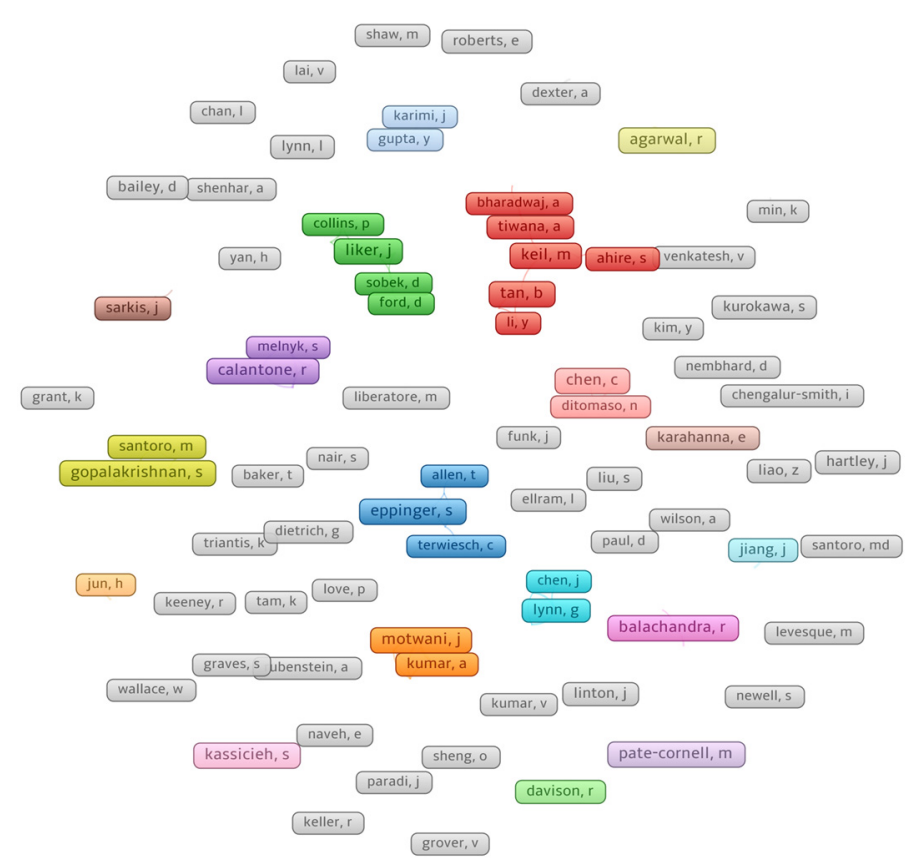

Figure 5 - Main authors' distribution and connections for the period 1996 - 2006

\begin{tabular}{|l|l|l|l|l|}
\hline Author & ND & TC & Cluster & Links \\
\hline Liker, J & 5 & 280 & 2 & 4 \\
\hline Eppinger, S & 4 & 559 & 3 & 3 \\
\hline Balachandra, R & 4 & 345 & 9 & 2 \\
\hline Calantone, R & 4 & 269 & 5 & 4 \\
\hline Tan, B & 4 & 229 & 13 & 3 \\
\hline Agarwal, R & 4 & 189 & 14 & 2 \\
\hline Keil, M & 4 & 161 & 1 & 3 \\
\hline Gopalakrishnan, S & 4 & 160 & 4 & 3 \\
\hline Chen, C & 4 & 148 & 10 & 2 \\
\hline Motwani, J & 4 & 144 & 7 & 3 \\
\hline Kassicieh, S & 4 & 76 & - & 1 \\
\hline Pate-Cornell, M & 4 & 44 & 15 & 1 \\
\hline Browning, T & 3 & 964 & 3 & 1 \\
\hline Straub, D & 3 & 465 & - & 1 \\
\hline Karahanna, E & 3 & 366 & - & 1 \\
\hline Lynn, G & 3 & 278 & 6 & 3 \\
\hline Hartley, J & 3 & 252 & - & - \\
\hline Bierly, P & 3 & 219 & 4 & 2 \\
\hline Khalifa, M & 3 & 153 & 11 & 1 \\
\hline
\end{tabular}




\begin{tabular}{|l|l|l|l|l|}
\hline Walsh, S & 3 & 150 & - & 1 \\
\hline Ahire, S & 3 & 140 & 1 & 1 \\
\hline Santoro, M & 3 & 135 & 4 & 2 \\
\hline Sambamurthy, V & 3 & 133 & 14 & 1 \\
\hline Ravichandran, T & 3 & 123 & 1 & 2 \\
\hline Kumar, A & 3 & 117 & 7 & 3 \\
\hline Reisman, A & 3 & 106 & 7 & 3 \\
\hline Kurokawa, S & 3 & 102 & - & 0 \\
\hline Tiwana, A & 3 & 93 & 1 & 2 \\
\hline Davison, R & 3 & 80 & 11 & 2 \\
\hline Rai, A & 3 & 73 & 1 & 2 \\
\hline Linton, J & 3 & 70 & - & 0 \\
\hline Jiang, J & 3 & 65 & - & 1 \\
\hline Klein, G & 3 & 65 & - & 1 \\
\hline Sarkis, J & 3 & 60 & 8 & 2 \\
\hline Hull, F & 3 & 52 & 2 & 2 \\
\hline Roberts, E & 3 & 46 & - & 0 \\
\hline Farris, G & 3 & 40 & 10 & 2 \\
\hline Liao, Z & 3 & 37 & - & 0 \\
\hline Bailey, D & 3 & 26 & - & 0 \\
\hline Liu, S & 3 & 18 & - & 0 \\
\hline Lynn, L & 3 & 18 & - & 0 \\
\hline
\end{tabular}

Table 6 - Details of main authors' distribution and connections for the period 1996 - 2006 (with at least three documents)

As shown, from 1996 to 2006 we see a substantial increase in the collaboration network between scholars. The co-authorship analysis identified a large numer of clusters of authors. In particular, combining the data from Figure 5 and Table 6, we can see that Liker, J., who is the most prolific author in this time span, has a series of strong connections with Collins, P., Cristiano, J., Ford, D., Hull, F., and Sober, D., who belong to the same cluster of collaboration (2, green).

The next cluster of collaboration (3, blue), headed by Eppinger, S., is comprised of Allen, T., Browning, T., Pich, M., Sosa, M., and Terwiesch, C., and this is the first one in which there are a number of citations showing that this group of authors are particularly productive and have significant impact in the field of engineering management. Similar evidence can be seen in Cluster 9 (pink), which is comprised of three authors (Balachandra, R., Friar, J., and Nellore, R.). Even though the cluster consists of only three authors, it is one of the most influential networks of collaborations.

Next, we analyze each country's distribution for the period between 1996 and 2006, showing a series of new contributors publishing in the journal. 


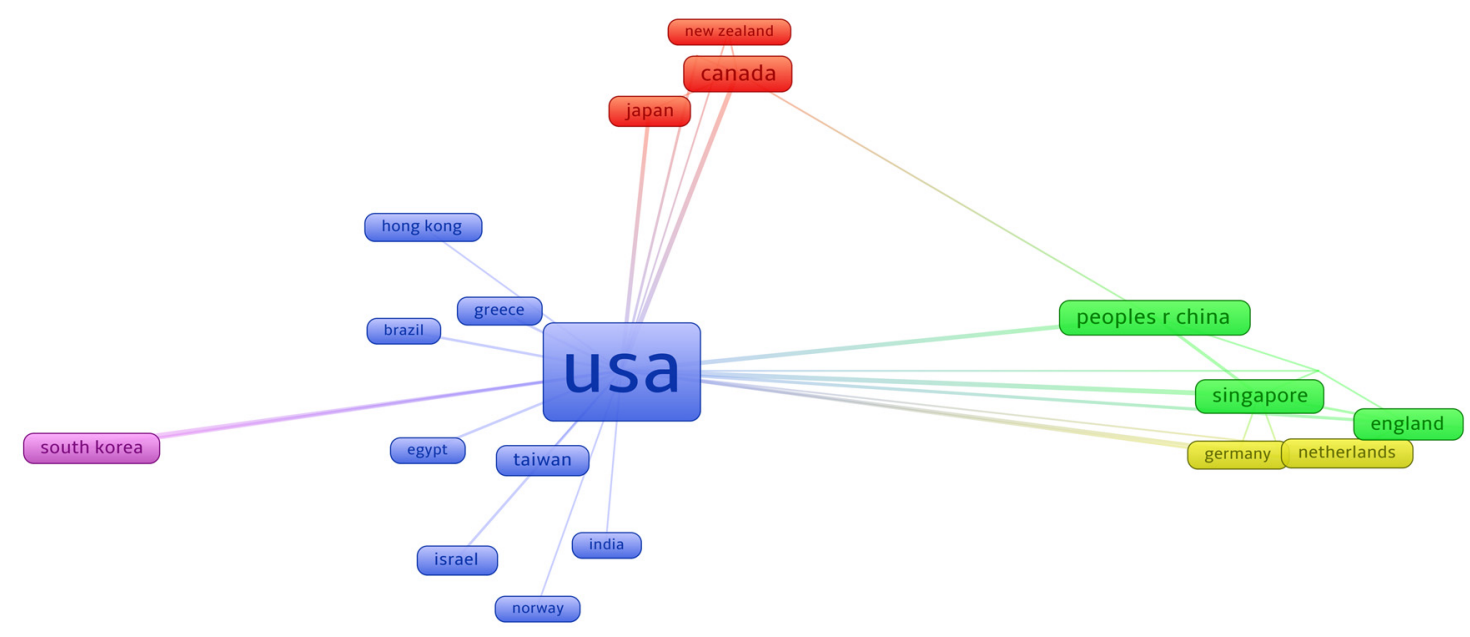

Figure 6 - Main countries' distribution and connections for the period 1996 - 2006

\begin{tabular}{|l|l|l|l|l|}
\hline Country & ND & TC & Cluster & Links \\
\hline USA & 290 & 11453 & 1 & 22 \\
\hline Canada & 26 & 868 & 3 & 5 \\
\hline Peoples R China & 22 & 571 & 2 & 4 \\
\hline Singapore & 17 & 649 & 2 & 6 \\
\hline England & 15 & 474 & 2 & 5 \\
\hline Japan & 9 & 161 & 3 & 2 \\
\hline South Korea & 9 & 312 & 5 & 2 \\
\hline Taiwan & 9 & 333 & 1 & 1 \\
\hline Israel & 7 & 206 & 1 & 1 \\
\hline Netherlands & 6 & 154 & 4 & 3 \\
\hline Australia & 5 & 130 & 2 & 4 \\
\hline France & 5 & 213 & 4 & 4 \\
\hline Germany & 5 & 292 & 4 & 3 \\
\hline Denmark & 4 & 192 & 5 & 2 \\
\hline Greece & 4 & 118 & 1 & 1 \\
\hline Hong Kong & 4 & 84 & 1 & 1 \\
\hline Scotland & 3 & 42 & 2 & 1 \\
\hline Switzerland & 3 & 160 & 5 & 3 \\
\hline
\end{tabular}

Table 7 - Details of main countries' distribution and connections for the period 1996 - 2006 (with at least three documents)

As shown in both Figure 6 and Table 7, in comparison to the same analysis for the period between 1985 and 1995 (Figure 3 and Table 4), it is evident that several new players have emerged as contributors to IEEE TEM. US and Canada based scholars remained the most prolific and influential scholars in the journal; however, there is a significant increase in Asia-Pacific based scholars (China, Singapore, Japan, South Korea, and Taiwan). Surprisingly, European based scholars are no longer the second most dominant group in the journal, with only England maintaining a fair position with 15 documents and 474 citations. Moreover, if we closely examine Figure 6, is possible to note that all of the scholars are connected to US based scholars. Despite this, the cluster analysis also shows that the Asia-Pacific based scholars are starting to cluster together, a trend that is also confirmed in the last round of analysis for the period between 2007 and 2017. 
In this time span, we have 562 papers indexed in the Web of Science Core Collection. Compared to the previous time span, the journal registered a positive difference of 144 more papers, with an increase of $+34.45 \%$ in the number of papers published throughout this period.

We can also see that the number of keywords (with at least five occurrences) moved from 25 for the period between 1996 and 2006 to 49 for 2007 to 2017, with an increase of $+96 \%$. This massive increase reflects the expansion of the range of topics covered by IEEE TEM and it is demonstrated in the following figure (Figure 7).

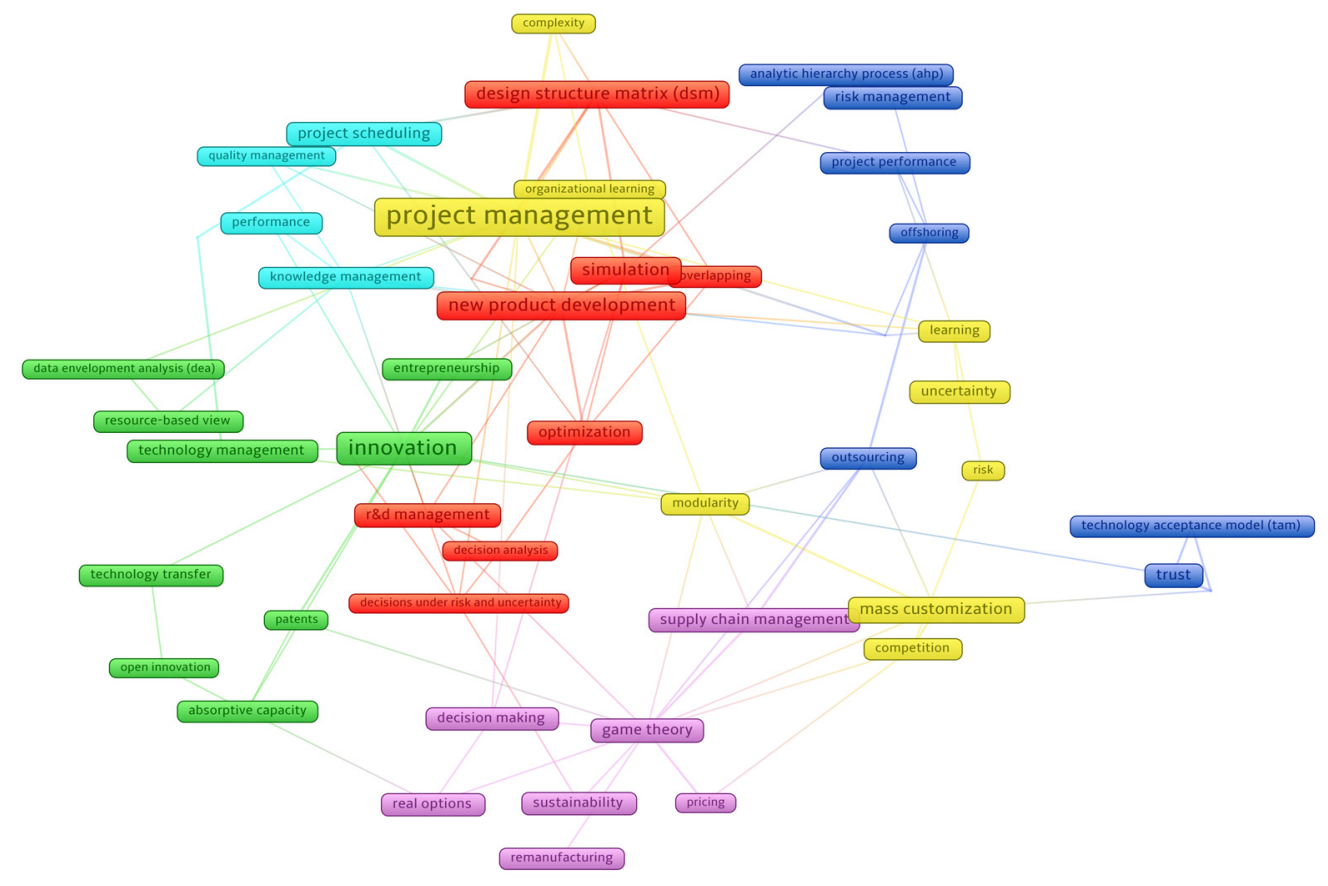

Figure 7 - Distribution of main keywords for the period 2007 - 2017

\begin{tabular}{|l|c|c|c|l|}
\hline Keyword & OC & Cluster & Links & APY \\
\hline project management & 31 & 5 & 19 & 2011,35 \\
\hline innovation & 23 & 1 & 11 & 2011,35 \\
\hline new product development & 17 & 3 & 11 & 2011,94 \\
\hline design structure matrix (dsm) & 14 & 3 & 7 & 2013,07 \\
\hline simulation & 14 & 3 & 12 & 2011,50 \\
\hline mass customization & 12 & 5 & 5 & 2007,67 \\
\hline optimization & 11 & 3 & 6 & 2014,55 \\
\hline trust & 11 & 2 & 3 & 2011,18 \\
\hline project scheduling & 11 & 6 & 6 & 2012,09 \\
\hline r\&d management & 10 & 3 & 9 & 2011,50 \\
\hline game theory & 10 & 4 & 12 & 2013,60 \\
\hline supply chain management & 10 & 4 & 5 & 2014,60 \\
\hline decision making & 9 & 4 & 4 & 2011,44 \\
\hline technology management & 8 & 1 & 6 & 2012,50 \\
\hline e-commerce & 8 & 2 & 3 & 2011,00 \\
\hline risk management & 8 & 2 & 4 & 2012,88 \\
\hline uncertainty & 8 & 5 & 4 & 2012,50 \\
\hline real options & 8 & 4 & 4 & 2012,25 \\
\hline sustainability & 8 & 4 & 4 & 2014,25 \\
\hline supply chain integration & 7 & 3 & 4 & 2013,57 \\
\hline absorptive capacity & 7 & 1 & 4 & 2012,43 \\
\hline outsourcing & 7 & 2 & 6 & 2011,57 \\
\hline learning & 7 & 5 & 6 & 2011,14 \\
\hline & & & & \\
\hline
\end{tabular}




\begin{tabular}{|l|l|l|l|l|}
\hline modularity & 7 & 5 & 7 & 2010,86 \\
\hline overlapping & 6 & 3 & 7 & 2014,17 \\
\hline entrepreneurship & 6 & 1 & 2 & 2010,67 \\
\hline resource-based view & 6 & 1 & 5 & 2011,17 \\
\hline technology transfer & 6 & 1 & 4 & 2009,33 \\
\hline analytic hierarchy process (AHP) & 6 & 2 & 2 & 2010,00 \\
\hline project performance & 6 & 2 & 5 & 2012,33 \\
\hline software development & 6 & 2 & 6 & 2008,83 \\
\hline technology acceptance model (TAM) & 6 & 2 & 3 & 2010,33 \\
\hline competition & 6 & 5 & 4 & 2012,17 \\
\hline remanufacturing & 6 & 4 & 4 & 2013,83 \\
\hline knowledge management & 6 & 6 & 7 & 2012,00 \\
\hline performance & 6 & 6 & 3 & 2011,17 \\
\hline decision analysis & 5 & 3 & 3 & 2012,80 \\
\hline decisions under risk and uncertainty & 5 & 3 & 5 & 2014,40 \\
\hline organization design & 5 & 3 & 7 & 2013,20 \\
\hline data envelopment analysis (DEA) & 5 & 1 & 2 & 2012,80 \\
\hline open innovation & 5 & 1 & 2 & 2011,80 \\
\hline patents & 5 & 1 & 5 & 2011,80 \\
\hline offshoring & 5 & 2 & 4 & 2012,20 \\
\hline complexity & 5 & 5 & 3 & 2010,60 \\
\hline organizational learning & 5 & 5 & 5 & 2011,20 \\
\hline risk & 5 & 5 & 3 & 2012,80 \\
\hline pricing & 5 & 4 & 5 & 2014,00 \\
\hline project planning & 5 & 6 & 4 & 2011,40 \\
\hline quality management & 5 & 6 & 6 & 2012,80 \\
\hline
\end{tabular}

Table 8 - Details of the distribution of main keywords for the period 2007 - 2017

As demonstrated in Figure 7, the topics covered by the journal are still centered around the three pillars founded in the previous period, namely "project management," "innovation," and "new product development" (viz. Figure 4). However, it is possible to observe a series of new topics emerging within the clusters, along with the simultaneous evolution of the other clusters and a huge series of new connections between the keywords.

In particular, the yellow cluster (number 5), related to project management, is now expanded; with a series of new topics, such as "mass customization", "learning", "modularity", "competition", "complexity", "organizational learning", and "risk" showing a shift towards a dynamic and organizational approach to project management.

On the other hand, the green cluster (number 1), related to innovation, is now enriched with new keywords such as "absorptive capacity," "entrepreneurship," "resource-based view," and "open innovation," again showing a shift towards a more dynamic approach to innovation. In fact, most of these terms come from the field of strategic management and, more generally, from business studies. In terms of the red cluster (number 3), related to new product development, is it possible to note the rise of new keywords strongly connected with each other ("design structure matrix (dsm)", "simulation", "optimization", "R\&D management", "decision analysis", "decisions under risk and uncertainty", and "organization design"), showing that the role of risk and uncertainty has now become a predominant topic connected to new product development and R\&D management. Again, this evidences a switch from the static perspective prevalent between 1996 and 2006 to the more dynamic perspective of more recent times.

The purple cluster (number 4) is mainly focused on "game theory," "supply chain management," and "decision making." In fact, game theory has become an essential tool in the analysis of supply chains with multiple agents, often with conflicting objectives [28]. This is evidenced by the fact that other keywords in the cluster are "real options," "sustainability," and "remanufacturing." All of these keywords represent a new kind of challenge for the domain of supply chain management in the future. Moreover, it is important to note that supply chain management is now a new cluster in itself, showing the rising importance of this topic within IEEE TEM. 
The azure cluster (number 6) is a new small cluster in which a series of new topics are connected. These topics gravitate around the domain of "project scheduling", with sub-topics related to "knowledge management", "performance", "project planning", and "quality management".

Finally, the blue cluster (number 2) can be seen to evolve differently. In fact, in the previous period (1996 - 2006), the central keyword in the cluster was "technology management", which has now moved into the green cluster (1), under the domain of innovation. "Supply chain management" has also moved to the pink cluster (4). The blue cluster is thus now focused on topics such as "trust", "ecommerce", "risk management", "outsourcing", "project performance", "software development", and "technology acceptance model (tam)" together with the the already present keyword "analytic hierarchy process (ahp)". This highlights the fact that the blue cluster is a group of residual topics that are connected with the other clusters but not necessarily connected with each other.

Analysis of the keywords emerging in the last period shows a substantial evolution of the topic identified in the previous period (1996 - 2006).

The evolution of keywords is also connected with the evolution of the co-authorship networks shown in the following figure (Figure 8).

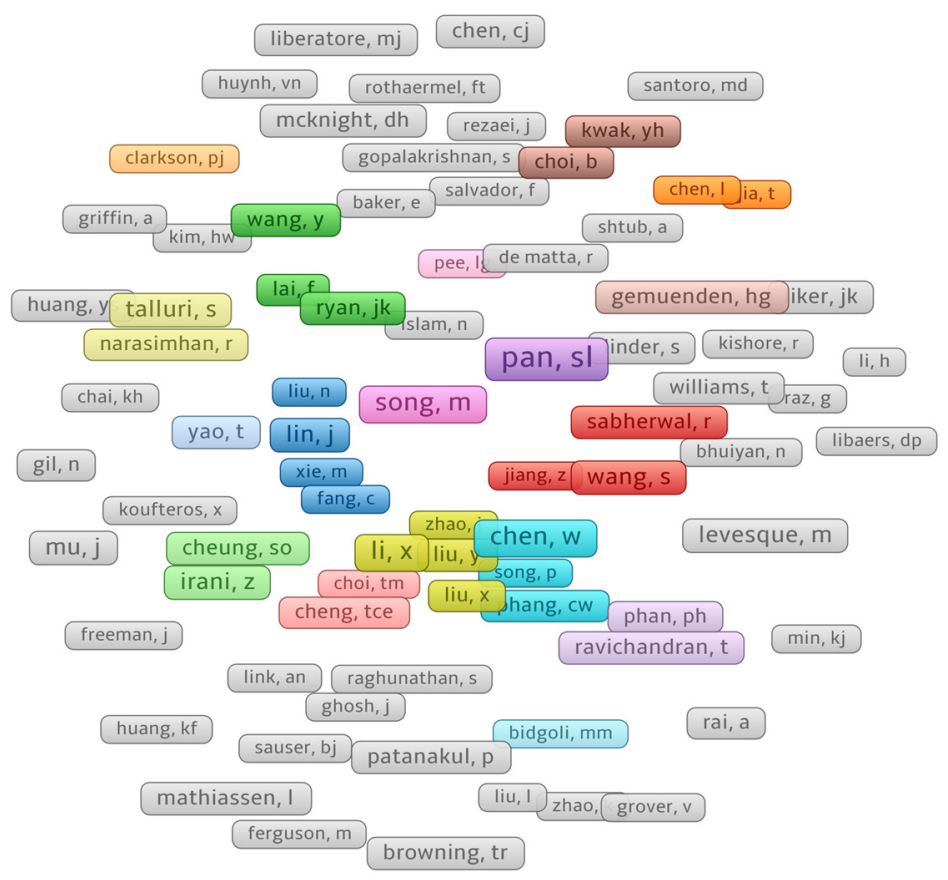

Figure 8 - Distribution of main authors and connections for the period 2007 2017

\begin{tabular}{|l|r|r|r|r|}
\hline Author & ND & TC & Cluster & Links \\
\hline Pan, Sl & 9 & 83 & 5 & 4 \\
\hline Song, M & 6 & 93 & 9 & 3 \\
\hline Li, X & 6 & 45 & 4 & 4 \\
\hline Chen, W & 6 & 43 & 6 & 4 \\
\hline Irani, Z & 5 & 145 & 11 & 3 \\
\hline Talluri, S & 5 & 106 & 13 & 2 \\
\hline Mu, J & 5 & 46 & -- & 1 \\
\hline Lin, J & 5 & 32 & 3 & 3 \\
\hline Wang, S & 5 & 25 & 1 & 6 \\
\hline Levesque, M & 5 & 17 & -- & 2 \\
\hline Mcknight, Dh & 4 & 147 & -- & 2 \\
\hline Love, Ped & 4 & 144 & 11 & 3 \\
\hline
\end{tabular}




\begin{tabular}{|c|c|c|c|c|}
\hline Liker, Jk & 4 & 108 & 22 & 2 \\
\hline Ro, Yk & 4 & 108 & 22 & 2 \\
\hline Sabherwal, R & 4 & 99 & 1 & 2 \\
\hline Chen, $\mathrm{Cj}$ & 4 & 95 & -- & 1 \\
\hline Browning, Tr & 4 & 90 & -- & 1 \\
\hline Gemuenden, $\mathrm{Hg}$ & 4 & 80 & -- & 2 \\
\hline Mathiassen, L & 4 & 79 & -- & 0 \\
\hline Thatcher, Jb & 4 & 68 & -- & 2 \\
\hline Wagner, Sm & 4 & 61 & -- & 0 \\
\hline Zhao, $\mathrm{X}$ & 4 & 58 & 2 & 4 \\
\hline Patanakul, $\mathrm{P}$ & 4 & 42 & -- & 2 \\
\hline Ravichandran, $\mathrm{T}$ & 4 & 38 & -- & 2 \\
\hline Zhang, X & 4 & 36 & 1 & 4 \\
\hline Cheung, So & 4 & 35 & 11 & 3 \\
\hline Yao, T & 4 & 27 & -- & 3 \\
\hline Ryan, Jk & 4 & 25 & 2 & 3 \\
\hline Wang, Y & 4 & 24 & 2 & 2 \\
\hline Liu, Y & 4 & 22 & 4 & 5 \\
\hline Chan, Hc & 4 & 8 & 3 & 2 \\
\hline Edwards, Dj & 3 & 126 & 11 & 2 \\
\hline Fixson, Sk & 3 & 103 & -- & 2 \\
\hline Williams, T & 3 & 102 & -- & 0 \\
\hline Rai, A & 3 & 73 & -- & 2 \\
\hline Tiwana, $\mathrm{A}$ & 3 & 66 & -- & 2 \\
\hline Phan, $\mathrm{Ph}$ & 3 & 56 & -- & 1 \\
\hline Di Benedetto, $\mathrm{Ca}$ & 3 & 49 & 9 & 2 \\
\hline Kwak, Yh & 3 & 47 & 8 & 2 \\
\hline $\mathrm{Li}, \mathrm{Y}$ & 3 & 43 & 4 & 5 \\
\hline Ramirez-Marquez, Je & 3 & 38 & -- & 1 \\
\hline Pan, $\mathrm{G}$ & 3 & 37 & 5 & 1 \\
\hline Lai, F & 3 & 35 & 2 & 2 \\
\hline Zhang, C & 3 & 35 & 4 & 6 \\
\hline Liberatore, $\mathrm{Mj}$ & 3 & 34 & -- & 0 \\
\hline Narasimhan, $\mathrm{R}$ & 3 & 30 & -- & 1 \\
\hline Tseng, Mm & 3 & 29 & 2 & 2 \\
\hline Park, J & 3 & 27 & 8 & 3 \\
\hline Qian, Y & 3 & 24 & 3 & 2 \\
\hline Gil, N & 3 & 21 & -- & 1 \\
\hline Tan, Bcy & 3 & 20 & 1 & 3 \\
\hline Parry, Me & 3 & 19 & 9 & 2 \\
\hline Choi, B & 3 & 17 & 8 & 1 \\
\hline Yiu, Tw & 3 & 17 & -- & 1 \\
\hline Nair, A & 3 & 16 & 9 & 1 \\
\hline Cheng, Tce & 3 & 14 & 10 & 4 \\
\hline $\mathrm{Li}, \mathrm{G}$ & 3 & 11 & 10 & 2 \\
\hline Chen, J & 3 & 10 & 1 & 3 \\
\hline Liu, $X$ & 3 & 10 & 4 & 3 \\
\hline Huang, Ys & 3 & 10 & -- & 1 \\
\hline Phang, $\mathrm{Cw}$ & 3 & 9 & 6 & 3 \\
\hline Tan, Ch & 3 & 8 & 6 & 2 \\
\hline Lee, Jn & 3 & 8 & 8 & 2 \\
\hline Wang, Z & 3 & 6 & 5 & 2 \\
\hline Linder, $\mathrm{S}$ & 3 & 5 & -- & 0 \\
\hline
\end{tabular}

Table 9 - Details of distribution of main authors and connections for the period 2007 - 2017 (with at least three documents)

It is clear to see from both Figure 8 and Table 9 that there is a strong increase in the numbers of authors with a least three documents published on IEEE TEM. In fact, in the period from 1996 to 
2006, there were 41 authors with at least three documents published, whereas in the last period there were 65 authors with at least three documents published; showing an increase of $+58.54 \%$. Thus, the IEEE TEM community has substantially increased during the last ten years, particularly in terms of its Asia-Pacific scholars. This is especially evident in the next figure (Figure 9), where we focused on the main nodes found in author collaborations.

However, despite the increase in the number of Asia-Pacific scholars, and their high productivity (note that they occupy the first four positions in Table 9), most of the citations still belong to western scholars (viz. Irani, Z.; Talluri, S.; Mcknight, Dh.; Love, P.; Liker, Jk.; Ro, Yk.; Sabherwal, R.).

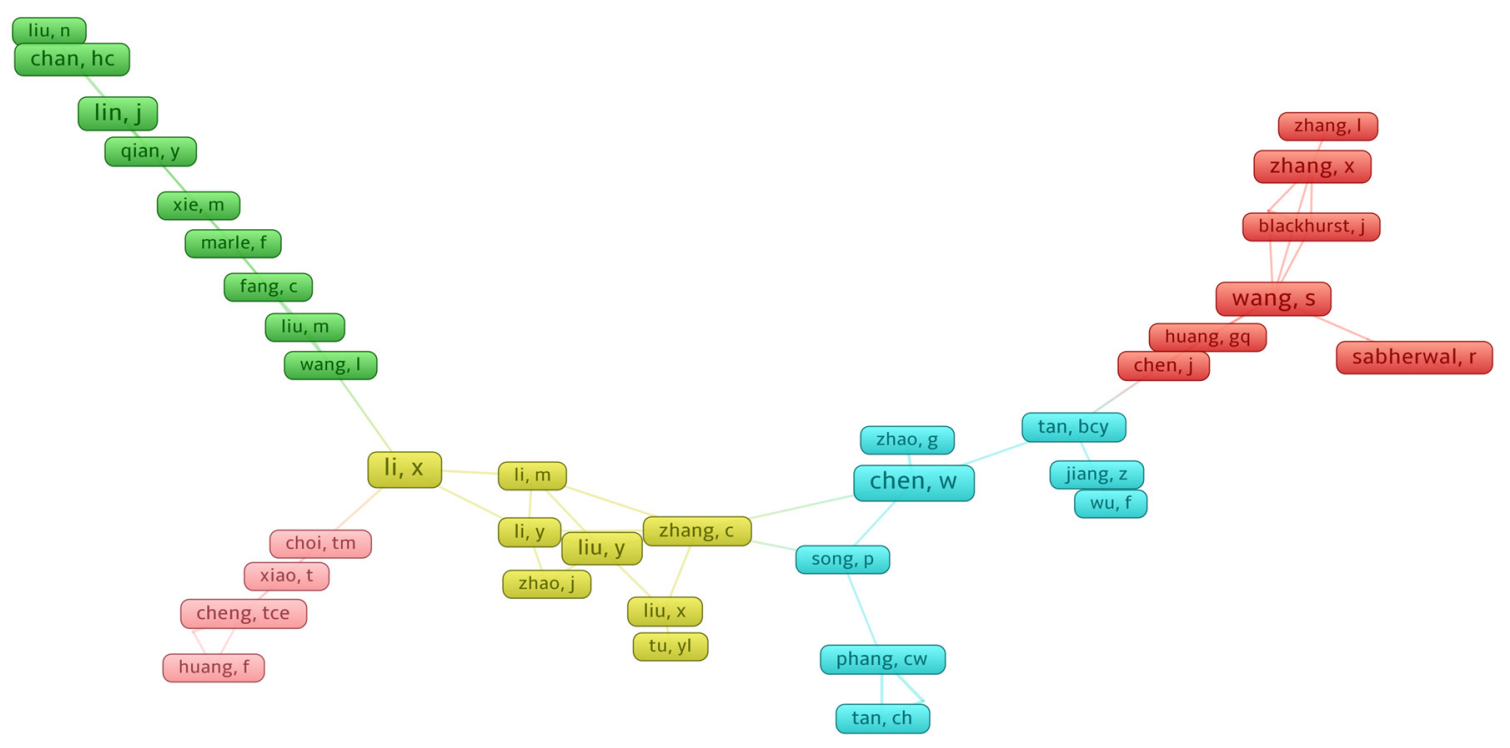

Figure 9 - Details of the central nodes of authors' distribution and connections for the period 2007 - 2017

\begin{tabular}{|l|r|r|r|r|}
\hline Author & ND & TC & Cluster & Links \\
\hline Li, X & 6 & 45 & 4 & 4 \\
\hline Chen, W & 6 & 43 & 3 & 4 \\
\hline Lin, J & 5 & 32 & 2 & 3 \\
\hline Wang, S & 5 & 25 & 1 & 6 \\
\hline Sabherwal, R & 4 & 99 & 1 & 2 \\
\hline Zhang, X & 4 & 36 & 1 & 4 \\
\hline Liu, Y & 4 & 22 & 4 & 5 \\
\hline Chan, Hc & 4 & 8 & 2 & 2 \\
\hline Li, Y & 3 & 43 & 4 & 5 \\
\hline Zhang, C & 3 & 35 & 4 & 6 \\
\hline Qian, Y & 3 & 24 & 2 & 2 \\
\hline Tan, Bcy & 3 & 20 & 3 & 3 \\
\hline Cheng, Tce & 3 & 14 & 5 & 4 \\
\hline Li, G & 3 & 11 & 5 & 2 \\
\hline Chen, J & 3 & 10 & 1 & 3 \\
\hline Liu, X & 3 & 10 & 4 & 3 \\
\hline Phang, Cw & 3 & 9 & 3 & 3 \\
\hline Tan, Ch & 3 & 8 & 3 & 2 \\
\hline Tu, Y1 & 2 & 45 & 4 & 1 \\
\hline Wu, F & 2 & 41 & 3 & 1 \\
\hline Huang, Gq & 2 & 38 & 1 & 2 \\
\hline Bock, Gw & 2 & 36 & 1 & 1 \\
\hline Li, M & 2 & 29 & 4 & 4 \\
\hline Hsu, Ic & 2 & 27 & 1 & 2 \\
\hline Xie, M & 2 & 22 & 2 & 4 \\
\hline
\end{tabular}




\begin{tabular}{|l|r|r|r|r|}
\hline Fang, C & 2 & 20 & 2 & 4 \\
\hline Zhang, L & 2 & 19 & 1 & 1 \\
\hline Blackhurst, J & 2 & 18 & 1 & 3 \\
\hline Wu, T & 2 & 18 & 1 & 3 \\
\hline Zhao, J & 2 & 17 & 4 & 2 \\
\hline Song, P & 2 & 16 & 3 & 3 \\
\hline Liu, M & 2 & 14 & 2 & 2 \\
\hline Marle, F & 2 & 11 & 2 & 2 \\
\hline Wang, L & 2 & 11 & 2 & 3 \\
\hline Choi, Tm & 2 & 8 & 5 & 3 \\
\hline Huang, F & 2 & 8 & 5 & 2 \\
\hline Jiang, Z & 2 & 8 & 3 & 2 \\
\hline Sutanto, J & 2 & 8 & 3 & 2 \\
\hline Xiao, T & 2 & 8 & 5 & 2 \\
\hline Liu, N & 2 & 7 & 2 & 1 \\
\hline Zhao, G & 2 & 1 & 3 & 1 \\
\hline
\end{tabular}

Table 10 - Details of the central nodes of authors' distribution and connections for the period 2007 - 2017 (with at least two documents)

However, Figure 9 and Table 10 demonstrate that Asia-Pacific scholars are able to create better and stronger networks of collaboration in comparison to western authors. In fact, as Figure 9 shows, the five clusters of authors are strongly interconnected, laying the foundations for a future predominance of Asia-Pacific scholars in IEEE TEM. This evidence is also shown by the distribution of countries in Figure 10.

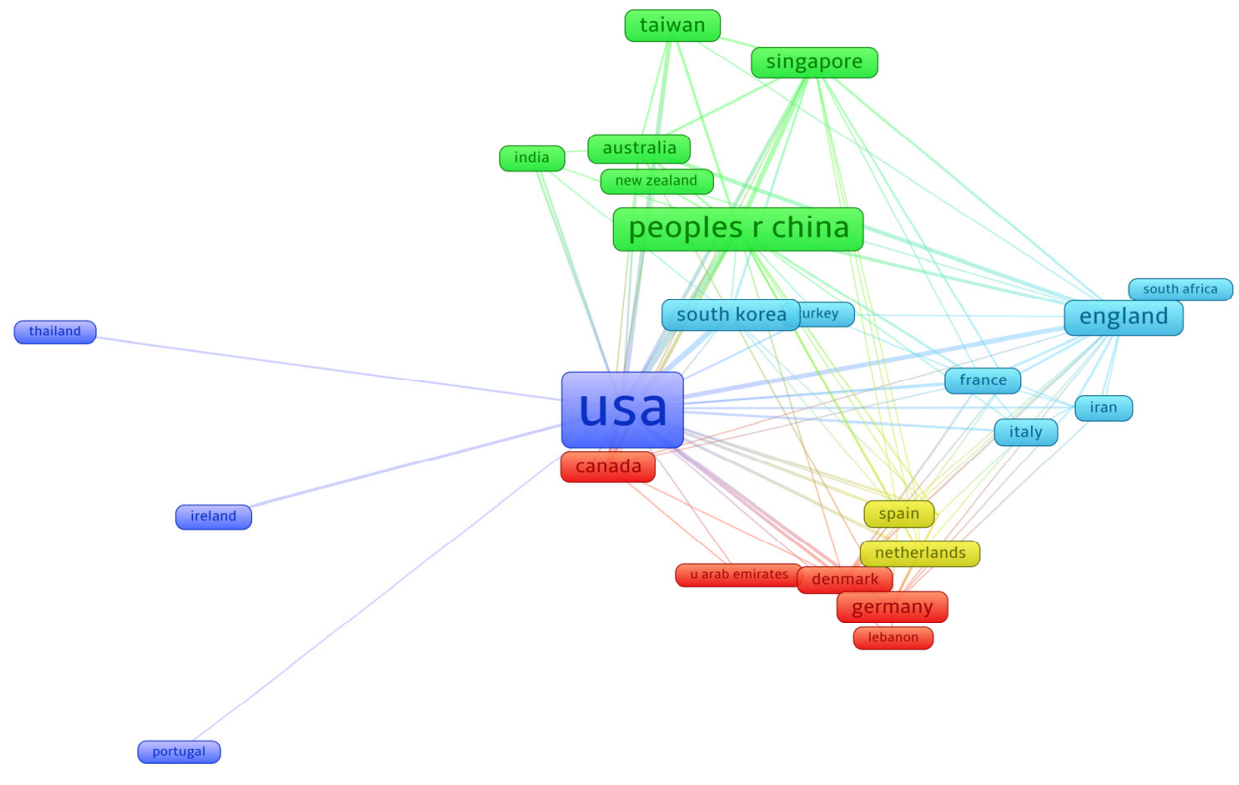

Figure 10 - Main countries' distribution and connections for the period 2007 - 2017

\begin{tabular}{|l|l|l|l|l|}
\hline Country & ND & TC & Cluster & Links \\
\hline USA & 291 & 3420 & 1 & 26 \\
\hline Peoples R China & 99 & 820 & 2 & 17 \\
\hline England & 54 & 770 & 5 & 20 \\
\hline Taiwan & 39 & 364 & 2 & 5 \\
\hline Singapore & 38 & 267 & 2 & 13 \\
\hline Canada & 34 & 290 & 3 & 11 \\
\hline Germany & 30 & 554 & 3 & 11 \\
\hline
\end{tabular}




\begin{tabular}{|l|l|l|l|l|}
\hline South Korea & 30 & 399 & 5 & 9 \\
\hline Australia & 20 & 289 & 2 & 9 \\
\hline Spain & 15 & 179 & 4 & 10 \\
\hline Netherlands & 15 & 113 & 4 & 8 \\
\hline Italy & 13 & 89 & 5 & 5 \\
\hline France & 13 & 75 & 5 & 10 \\
\hline Denmark & 12 & 257 & 3 & 11 \\
\hline Switzerland & 11 & 124 & 4 & 8 \\
\hline Iran & 11 & 35 & 5 & 4 \\
\hline India & 9 & 64 & 2 & 4 \\
\hline Sweden & 7 & 134 & 5 & 6 \\
\hline Israel & 6 & 79 & 3 & 2 \\
\hline Turkey & 5 & 86 & 5 & 4 \\
\hline Belgium & 5 & 33 & 4 & 9 \\
\hline Wales & 4 & 68 & 5 & 3 \\
\hline New Zealand & 4 & 54 & 2 & 4 \\
\hline Norway & 4 & 46 & 5 & 7 \\
\hline Finland & 4 & 34 & 2 & 3 \\
\hline Japan & 4 & 33 & 2 & 1 \\
\hline Ireland & 4 & 11 & 1 & 1 \\
\hline Portugal & 3 & 96 & 1 & 1 \\
\hline Austria & 3 & 67 & 3 & 2 \\
\hline
\end{tabular}

Table 11 Details of main countries' distribution and connections for the period 2007 - 2017 (with at least three documents)

As can be seen in Figure 10 and Table 11, the evolution of the collaborative networks within countries has moved in the direction predicted in the previous period under analysis (see Figure 6). In fact, Figure 10 shows the polarization of the authors' network in four areas. The first and central (blue, Cluster 1) is again dominated by US-based scholars, who are the still the most productive (291 documents) and the most cited (3420 citations). The US is the central node which connects all of the other clusters. This means that most of the papers have at least one US-based scholar. The second cluster (green, Cluster 2) shows that the whole Asia-Pacific area belongs to this cluster. This is in line with what was found in the author network collaborations. However, the scholars from the Republic of China are now the second most productive (99 papers) and cited (820 citations) scholars in the database.

Moreover, it is clear to see that European scholars are polarized in three clusters. The azure cluster (Cluster 5) is headed by England, the red cluster (Cluster 3) is headed by Canada and Germany, and finally, the smaller yellow cluster (Cluster 4) is headed by Spain and the Netherlands.

\section{Conclusion}

In this paper we have analyzed the evolution of IEEE TEM from 1985 to 2007. The bibliometric analysis showed that a series of fundamental changes have happened over these years. These changes are mostly related to the topics covered by the journal and the affiliations of the authors. In particular, the keyword analysis showed that the topics analyzed by IEEE TEM orbit around the main topic of project management. However, during recent years, we have identified a substantial rise in new topics such as innovation, new product development, and supply chain management. Moreover, we recorded interesting evolutions in authorship collaborations during the period under analysis.

In particular, across the years the IEEE TEM created small groups of authors who developed specific topics and, in recent times, assisted in the strengthening of collaborations within Asia-Pacific scholars. This evidence is also confirmed by the countries' distributions and connections, where we highlight that scholars from the Republic of China can be considered the rising stars of the journals, while European scholars can be seen to slowly lose their position of dominance to scholars with the USA. 
Following the new direction in which the editor would like to orientate IEEE TEM, placing the main focus on Engineering Management, Emerging Technologies, and Technology Management, we can assume that the trend shown by keywords analysis will be amplified. In fact, we have assisted in increasing the expansion in terms of topics connected with fields of research, such as Innovation, R\&D Management, and Project Management.

Moreover, the new focus on artificial intelligence, internet of things, and space travel will beneficially express the coverage of the journal among the three aforementioned areas of research. Moving on from these premises it is possible that, in the near future, new specialized fields of studies linked to the new direction of IEEE TEM will emerge within the journal, along with topics such as "mass customization" and "software development". These will be analyzed by other journals, as the average publication year (APY) in Table 8 suggests.

In spite of the limitations of this study, it succeeds in simplifying a complex body of knowledge in an attempt to present it more succinctly. In doing so, some information is discarded in order to allow for a graphical representation of data. This can, therefore, be considered a snapshot of IEEE TEM, acting as a compass for the further exploration of certain topics.

In terms of future challenges for IEEE TEM, the new editor expressed a willingness to focus the journal on three main areas of interest; namely Engineering Management, Emerging Technologies, and Technology Management. The first will examine the best practices from successful projects and systems; challenges coming from regulations; policies; standards; and designs. The second will focus on technology assessment; forecasting; planning; transfers; the management of technology innovation; new product and service development; R\&D management; and entrepreneurship. The latter, which represents one of the most challenging areas of development, will address topics such as artificial intelligence, internet of things, and space travel.

\section{References}

[1] M. T. G. Merino, M. L. P. Do Carmo, and M. V. S. Álvarez, "25 Years of Technovation: Characterisation and evolution of the journal," Technovation, vol. 26, no. 12, pp. 1303-1316, 2006.

[2] J. L. Heck and W. G. Bremser, "Six decades of The Accounting Review: a summary of author and institutional contributors," Account. Rev., pp. 735-744, 1986.

[3] G. M. Zinkhan and T. W. Leigh, "Assessing the quality ranking of the journal of advertising, 1986-1997," J. Advert., vol. 28, no. 2, pp. 51-70, 1999.

[4] R. K. Yin, Case study research and applications: Design and methods. Sage publications, 2018.

[5] L. Richards and J. M. Morse, Readme first for a user's guide to qualitative methods. Sage, 2012.

[6] N. I. Fisher and W. R. Zwet, “An Interview with Jae C. Lee,” Int. Stat. Rev., vol. 83, no. 3, pp. 371-404, 2015.

[7] F. Nahai and E. S. Bernard, "20th Anniversary Interview With ASJ Editor-in-Chief Dr Foad Nahai." Oxford University Press, 2015.

[8] R. Schmidt-Radde, "Interview with the Editor," Chempluschem, vol. 81, no. 1, pp. 3-6, 2016.

[9] Y. Ding, R. Rousseau, and D. Wolfram, Measuring scholarly impact. Springer, 2016.

[10] M. E. Falagas, E. I. Pitsouni, G. A. Malietzis, and G. Pappas, "Comparison of PubMed, Scopus, web of science, and Google scholar: strengths and weaknesses," FASEB J., vol. 22, no. 2, pp. 338-342, 2008.

[11] I. Zupic and T. Čater, "Bibliometric methods in management and organization," Organ. Res. Methods, vol. 18, no. 3, pp. 429-472, 2015.

[12] K. Börner, C. Chen, and K. W. Boyack, "Visualizing knowledge domains," Annu. Rev. Inf. Sci. Technol., vol. 37, no. 1, pp. 179-255, 2003. 
[13] N. Coulter, I. Monarch, and S. Konda, "Software engineering as seen through its research literature: A study in co-word analysis," J. Am. Soc. Inf. Sci., vol. 49, no. 13, pp. 1206-1223, 1998.

[14] F. J. Acedo, C. Barroso, C. Casanueva, and J. L. Galán, "Co-authorship in management and organizational studies: An empirical and network analysis," J. Manag. Stud., vol. 43, no. 5, pp. 957-983, 2006.

[15] K. Lu and D. Wolfram, "Measuring author research relatedness: A comparison of word-based, topic-based, and author cocitation approaches," J. Assoc. Inf. Sci. Technol., vol. 63, no. 10, pp. 1973-1986, 2012.

[16] N. J. van Eck and L. Waltman, "Visualizing bibliometric networks," in Measuring scholarly impact, Springer, 2014, pp. 285-320.

[17] N. J. Van Eck and L. Waltman, "Software survey: VOSviewer, a computer program for bibliometric mapping," Scientometrics, vol. 84, no. 2, pp. 523-538, 2010.

[18] T. R. Browning, "Design Structure Matrix Extensions and Innovations: A Survey and New Opportunities," IEEE Trans. Eng. Manag., vol. 63, no. 1, pp. 27-52, Feb. 2016.

[19] R. Balachandra and J. H. Friar, "Factors for success in R\&D projects and new product innovation: A contextual framework," IEEE Trans. Eng. Manag., vol. 44, no. 3, pp. 276-287, 1997.

[20] J. K. Pinto and S. J. Mantel, "The causes of project failures," IEEE Trans. Eng. Manag., vol. 37, no. 4, pp. 269-276, Nov. 1990.

[21] U. Lichtenthaler, "Open innovation in practice: An analysis of strategic approaches to technology transactions," IEEE Trans. Eng. Manag., vol. 55, no. 1, pp. 148-157, Feb. 2008.

[22] A. B. Badiru, "Computational Survey Of Univariate And Multivariate Learning-Curve Models," IEEE Trans. Eng. Manag., vol. 39, no. 2, pp. 176-188, 1992.

[23] C. W. Craighead, D. J. Ketchen Jr., K. S. Dunn, and G. T. M. Hult, "Addressing Common Method Variance: Guidelines for Survey Research on Information Technology, Operations, and Supply Chain Management," IEEE Trans. Eng. Manag., vol. 58, no. 3, pp. 578-588, 2011.

[24] D. Gefen, E. Karahanna, and D. W. Straub, "Inexperience and experience with online stores: The importance of TAM and trust," IEEE Trans. Eng. Manag., vol. 50, no. 3, pp. 307-321, 2003.

[25] R. L. Keeney and D. Vonwinterfeldt, "Eliciting Probabilities From Experts In Complex Technical Problems," IEEE Trans. Eng. Manag., vol. 38, no. 3, pp. 191-201, 1991.

[26] A. D. Henriksen and A. J. Traynor, "A practical R\&D project-selection scoring tool," IEEE Trans. Eng. Manag., vol. 46, no. 2, pp. 158-170, 1999.

[27] M. A. Mustafa and J. F. Albahar, "Project Risk Assessment Using The Analytic Hierarchy Process," IEEE Trans. Eng. Manag., vol. 38, no. 1, pp. 46-52, Feb. 1991.

[28] G. P. Cachon and S. Netessine, "Game theory in supply chain analysis," in Models, methods, and applications for innovative decision making, INFORMS, 2006, pp. 200-233. 